\title{
On the development of B-Raf inhibitors acting through
}

\section{innovative mechanisms [version 1; peer review: 1 approved, 1}

\section{approved with reservations]}

\author{
Luca Pinzi (iD) \\ Department of Life Sciences, University of Modena and Reggio Emilia, Modena, Italy
}

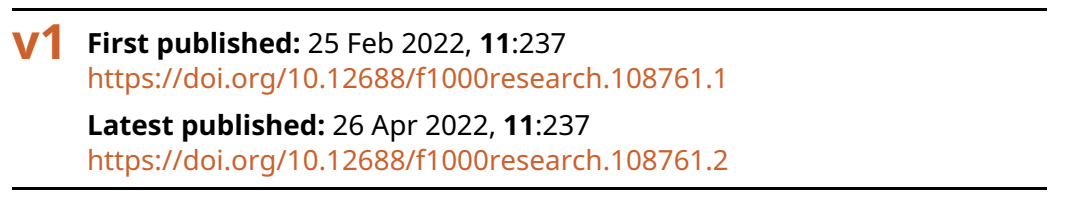

\section{Abstract}

B-Raf is a protein kinase participating to the regulation of many biological processes in cells. Recent studies have demonstrated that this protein is frequently overactivated in human cancers, especially when it bears activating mutations. In recent years, few ATPcompetitive inhibitors of B-Raf have been marketed for the treatment of melanoma and are currently under clinical evaluation on a variety of other types of cancer. Although the introduction of drugs targeting B-Raf has provided significant advances in cancer treatment, responses to such ATP-competitive inhibitors remain limited, mainly due to selectivity issues, side effects, narrow therapeutic windows, and the insurgence of drug resistance.

Impressive research efforts have been made so far towards the identification of novel ATP-competitive modulators with improved efficacy against cancers driven by mutant Raf monomers and dimers, some of them showing good premises. However, several limitations could still be envisioned for these compounds, according to recent literature data. Besides, increased attentions have recently arisen around approaches based on the design of allosteric modulators, polypharmacology, PROTACs and drug repurposing for the targeting of B-Raf proteins. The design of compounds acting through such innovative mechanisms is rather challenging. However, novel valuable therapeutic opportunities can be envisioned on these drugs, as they act through innovative mechanisms in which limitations typically observed for approved ATP-competitive B-Raf inhibitors are less prone to emerge. In this article, the most recent approaches adopted for the design of non-ATP competitive inhibitors targeting B-Raf are described, discussing also on the possibilities, ligands acting through such innovative mechanisms could provide for the obtainment of more effective therapies.

Keywords

B-Raf, allosteric inhibitors, polypharmacology, drug repurposing, PROTACs, drug discovery and development, small molecule inhibitors.

\section{Open Peer Review}

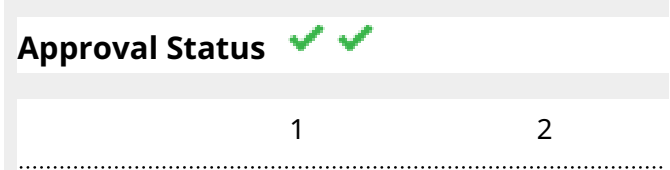

version 2

(revision)

26 Apr 2022

version 1

$25 \mathrm{Feb} 2022$

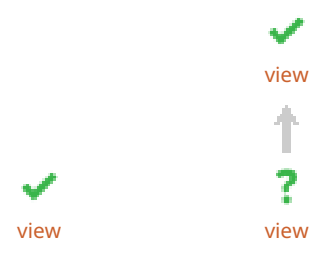

1. Federico Falchi iD, University of Bologna,

Bologna, Italy

2. Andrew Anighoro (D), Relation Therapeutics

LTD, London, UK

Any reports and responses or comments on the article can be found at the end of the article. 


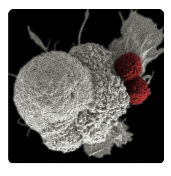

This article is included in the Oncology

gateway.

Corresponding author: Luca Pinzi (luca.pinzi@unimore.it)

Author roles: Pinzi L: Conceptualization, Writing - Original Draft Preparation, Writing - Review \& Editing

Competing interests: No competing interests were disclosed.

Grant information: Luca Pinzi was supported by a FIRC-AIRC fellowship for Italy [rif. 24096].

The funders had no role in study design, data collection and analysis, decision to publish, or preparation of the manuscript.

Copyright: @ 2022 Pinzi L. This is an open access article distributed under the terms of the Creative Commons Attribution License, which permits unrestricted use, distribution, and reproduction in any medium, provided the original work is properly cited.

How to cite this article: Pinzi L. On the development of B-Raf inhibitors acting through innovative mechanisms [version 1; peer review: 1 approved, 1 approved with reservations] F1000Research 2022, 11:237 https://doi.org/10.12688/f1000research.108761.1

First published: 25 Feb 2022, 11:237 https://doi.org/10.12688/f1000research.108761.1 
The Serine/Threonine protein kinase B-Raf is one among the most widely studied targets for cancer treatment. ${ }^{1,2}$ Under physiological conditions, this protein participates as key player in the Ras-Raf-MEK-ERK signaling pathway to the regulation of a number of cellular processes. ${ }^{3,4}$ In cancer cells, B-Raf is often upregulated, especially when it bears activating mutations, thus promoting oncogenic cellular processes as uncontrolled proliferation, tumor growth and metastasis. ${ }^{5-9}$ Of note, several studies have reported that B-Raf is frequently mutated in human cancers, ${ }^{6,10,11}$ with more than forty oncogenic mutations currently being described for this kinase. ${ }^{12}$ For these reasons, wild type (WT) and mutant B-Raf proteins have gained remarkable relevance for the development of anticancer drugs over the last years. Several drugs selectively targeting B-Raf proteins have also been approved for the treatment of metastatic melanoma, ${ }^{13,14}$ providing remarkable advantages in therapeutic regimens, and are currently under evaluation against colorectal cancer. ${ }^{15}$ However, the therapeutic use of the majority of these drugs is still hampered by drug resistance and side effects issues, resulting in responses that often remain temporary and rarely complete, the median time progression, e.g., for Vemurafenib against melanoma being six to seven months. ${ }^{16}$ In particular, recent findings have demonstrated that drug resistance often characterizing approved B-Raf inhibitors is mainly driven by feedback deregulation and overexpression of several other kinases. ${ }^{17-20}$ Nevertheless, clinical evidences have demonstrated that the use of selected B-Raf inhibitors in therapeutic regiments can also result in Raf paradoxical activation, which promotes cellular hyperproliferation of certain secondary skin lesions. ${ }^{21-26}$ In particular, it has been reported that when a B-Raf monomer is bound to specific inhibitors (e.g., Dabrafenib and Vemurafenib), it can dimerize promoting the aberrant activity of a second drug-free protomer, which cannot be targeted due to protein conformational rearrangements. ${ }^{21}$ This event in turn promotes abnormal proliferation in cells harboring other oncogenic mutations, through the activation of the MEK-ERK pathway. ${ }^{27}$ In this context, major research efforts have been devoted so far on the development of novel ATP-competitive kinase inhibitors binding to different $\alpha \mathrm{C}$-helix conformations of B-Raf (i.e., $\alpha \mathrm{C}$-OUT and $\alpha \mathrm{C}$-IN) (Figure 1). ${ }^{13,21,22,28,29}$ However, the obtainment of clinically safe ATP-competitive inhibitors showing high selectivity towards selected kinases is often elusive. With regards to B-Raf, low efficacy deriving by non-optimal therapeutic windows and the establishment of allosteric priming could be observed, for example, for $\alpha \mathrm{C}$-IN binders, albeit they can abrogate aberrant Raf dimerization-derived activities, through the inhibition of both the monomer and dimer of the kinase. ${ }^{13,30,31}$ Examples of recently reported compounds binding to this type of conformation of B-Raf are the pan-Raf inhibitors RAF-265, MLN-2480, TAK-632, LY3009120, CCT196969 and CCT241161, ${ }^{32-34}$ some of them having been evaluated in clinical trials (e.g., ClinicalTrials.gov identifiers: NCT02014116, NCT01425008 and NCT00304525), also in combination with MEK blockers (e.g., ClinicalTrials.gov identifier: NCT01352273). On the contrary, $\alpha \mathrm{C}-\mathrm{OUT}$ B-Raf inhibitors demonstrated to provide good selectivity profiles and wider therapeutic windows compared to $\alpha \mathrm{C}$-IN binders. ${ }^{13,13,28}$ Examples of such compounds are, among the others, Vemurafenib, Dabrafenib and Encorafenib, which potently inhibit mutant $\mathrm{B}-\mathrm{Raf}^{\mathrm{V} 600 \mathrm{E}}$ monomers, but resulted to be ineffective on tumor cellular contexts driven by aberrant Raf dimerization. ${ }^{13,28}$ Moreover, compounds binding to the $\alpha \mathrm{C}$-OUT conformation of $\mathrm{B}$-Raf have also been reported to promote paradoxical activation. ${ }^{13,35}$ Besides, other studies have been focused on the development of compounds as PLX7904 and PLX8394, able to escape paradoxical activation of B-Raf (i.e., the so-called "paradox breakers") and to overcome some of known resistance mechanisms associated to previously reported Raf inhibitors, ${ }^{36,37}$ the latter ligand currently being evaluated in Phase I/IIa clinical trials (ClinicalTrials.gov identifier: NCT02428712). The development of paradox breaker compounds is expected to provide significant impact to anticancer therapy, as they allow to efficiently modulate the activity of mutant B-Raf ${ }^{\mathrm{V} 600 \mathrm{E}}$, while circumventing protein dimerization. ${ }^{38}$ However, such compounds might also result in limited efficacy towards cancers with mutated Ras, according to recent literature data. ${ }^{38}$ Despite the advantages that can be observed in latest-generation ATP-competitive inhibitors of this kinase, several evidences encouraged a number of research groups to develop B-Raf modulators acting through innovative mechanisms. These include, for example, the modulation of the kinase activity of B-Raf with type III and IV highly selective allosteric binders, as well as through multi-target approaches (i.e., polypharmacology) (Figure 1). The design of allosteric kinase inhibitors of B-Raf is particularly challenging, for example, due to missing activity data or the lack of crystallographic structures suitable for the investigations, whose "activation loop", "activation segment" and " $\alpha$ C-helix" are often not clearly solved. However, recent advancements in crystallographic and in silico techniques will certainly help to overcome several of the issues currently encountered in kinase allosteric ligand design. ${ }^{39,40}$ The identification of allosteric inhibitors of B-Raf holds great premises in cancer therapy. Indeed, such targeting approaches are expected to help identifying ligands with higher selectivity towards B-Raf with respect to classic ATP-competitive binders, and to help to overcome drug resistance, similarly to as postulated for other kinases. ${ }^{41-45}$ Unfortunately, neither type III, nor type IV small molecule, allosteric modulators of B-Raf have been reported so far. However, potent type III inhibitors binding to an allosteric pocket in proximity to the regulatory $\alpha \mathrm{C}$-helix have been reported for several other kinases, such as BCR-ABL, MEK, EGFR and CDK2, ${ }^{46-52}$ providing valuable structural clues for the design of innovative B-Raf modulators. These results have also been fueled by the recent crystallographic resolution of type III allosteric inhibitors of mutant EGFR and MEK (e.g., see references 45,49,53). In this regard, our research group has recently reported the design of previously unseen type III allosteric inhibitors of the CDK2 kinase showing anticancer activity. ${ }^{46,54}$ Moreover, we have also reported the identification of structurally novel allosteric modulators of WT and double mutant EGFR, exhibiting inhibitory activity towards non-small cell lung cancer (NSCLC). ${ }^{47}$ More recently, our research group has demonstrated that B-Raf possesses an allosteric pocket similar to that 


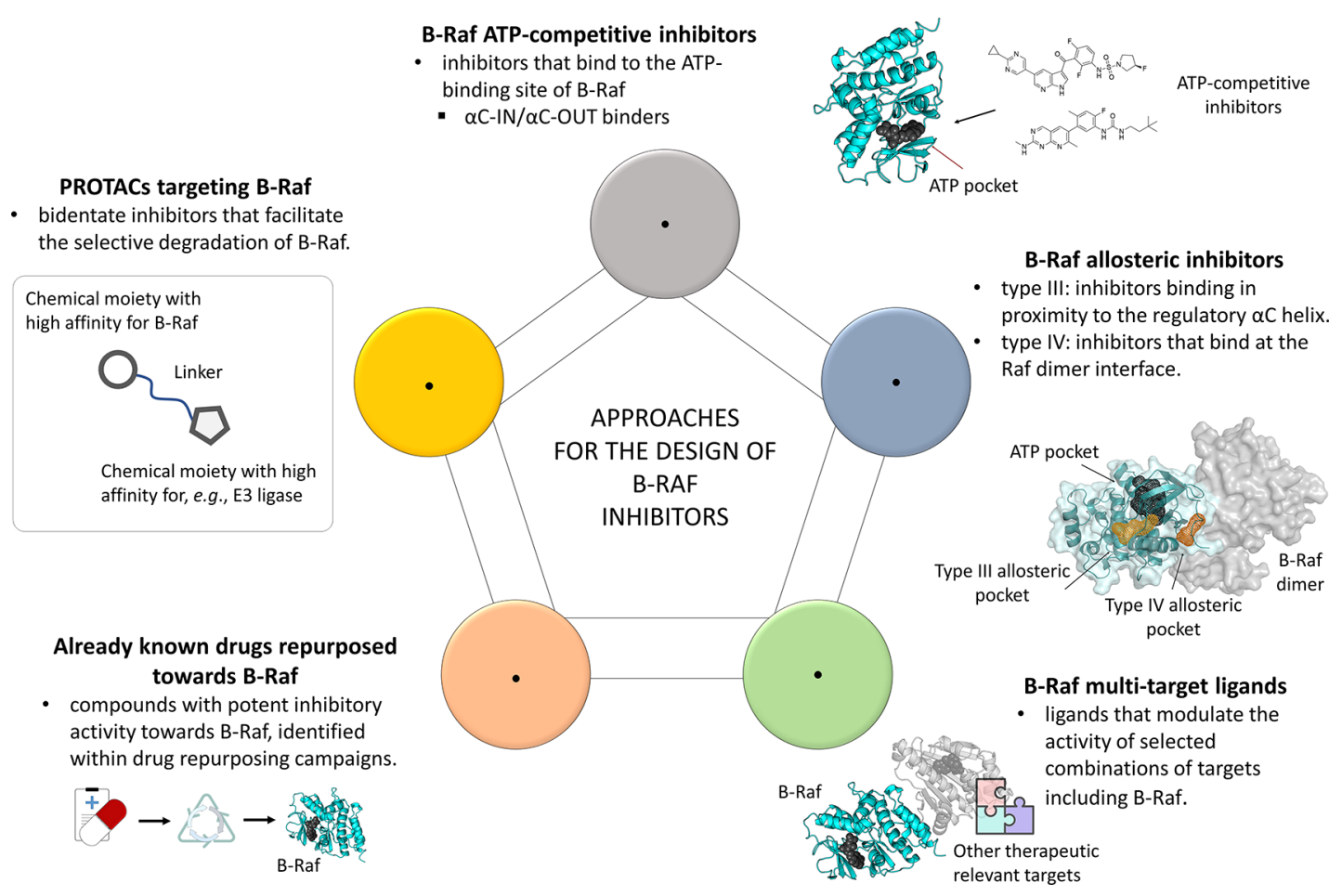

Figure 1. Schematic representation of the approaches currently pursued for the design of B-Raf ligands, discussed in the article.

of EGFR ${ }^{\mathrm{T} 790 \mathrm{M}}$, adopting a DFG-IN/ $\alpha \mathrm{C}-\mathrm{OUT}$ conformation potentially druggable by type III modulators. ${ }^{55}$ Remarkably, the presence of such allosteric pocket in B-Raf has also been indirectly confirmed in a recent study by Cotto-Rios et al. ${ }^{56}$ In particular, in their study the authors firstly identified Ponatinib as an inhibitor of B-Raf within a drug repositioning campaign, this compound presenting a methyl-piperazine moiety that allocated into the allosteric site in proximity to the kinase regulatory $\alpha \mathrm{C}$-helix. Then, medicinal chemistry optimizations were also performed on Ponatinib, leading to the identification of a compound (i.e., PHI1) that showed selectivity towards Raf dimers in cancer cells. ${ }^{56}$ Together with previous considerations and literature data, the results of this study suggest that the design of allosteric inhibitors of B-Raf is feasible. Moreover, these results also suggest that the design of such allosteric ligands would also open to novel strategies enabling the full arrest of the B-Raf kinase activity, potentially either via single agents or combination therapies. Nevertheless, the results prospected in this study paved the way towards the identification of innovative B-Raf inhibitors among approved drugs (i.e., drug repurposing) (Figure 1), ${ }^{56,57}$ this approach being already navigated also with natural products and clinically safe candidates, on different medicinal chemistry research areas. ${ }^{58-64}$ Similar considerations can also be argued for the design of allosteric ligands binding to the B-Raf dimer interface (i.e., type IV). The interest on such type IV allosteric ligands for the targeting of both wild type and mutant B-Raf has steadily increased over the past few years, with a number of small polypeptides able to disrupt protein dimerization and transactivation being reported. ${ }^{43,44,65,66}$ In particular, Beneker et al. ${ }^{43}$ were among the first to report the identification of a small set of polypeptides binding to the Raf dimerization interface. The results achieved in their study not only demonstrated that such a type of targeting is a feasible endeavor on B-Raf, but also that type IV allosteric ligands could provide remarkable results when used in combination with known mutant-selective ATP-competitive inhibitors promoting paradoxical activation of the ERK signaling. ${ }^{43}$ On the same line, Gunderwala et al. ${ }^{44}$ more recently reported the identification of Braftide, a small polypeptide designed through a computational strategy blocking Raf dimerization. Notably, Braftide demonstrated to efficiently inhibit Raf dimerization and to provide degradation of the MAPK complex. Moreover, Braftide has also proved to synergize with Vemurafenib and Dabrafenib, ${ }^{44}$ further supporting the potential application of type IV allosteric B-Raf inhibitors on therapeutic regiments with approved ATP-competitive drugs. The possibility to identify allosteric ligands of this kinase could also open to novel therapeutic approaches promoting simultaneous blockade of B-Raf at different sites, for example, if used in combination with approved ATP-competitive drugs. Indeed, such a complementary therapeutic approach is being under study against EGFR-mutant lung cancer, ${ }^{52}$ and it is expected to provide also valuable opportunities for B-Raf targeting. Allosteric inhibitors acting at a site different to those of the type III and type IV ligands described above have already been investigated for other kinases, in some cases with promising results. ${ }^{67}$ In the specific 
case of B-Raf, the identification of these types of inhibitors is still at a preliminary stage, albeit remarkable therapeutic opportunities arising on these grounds could be envisioned for the near future.

Novel valuable opportunities could also arise from the identification of compounds exhibiting activity on B-Raf, in selected combinations of targets. The therapeutic advantages deriving by the simultaneous modulation of multiple targets involved in the physiopathology of a disease, either by using a combination of drugs, or with ligands endowed with tailored polypharmacology properties, have already extensively discussed in literature. ${ }^{68-71}$ Indeed, the use of approved B-Raf inhibitors is now mainly framed in combined regiments including modulators of other therapeutic relevant targets. For example, the B-Raf ${ }^{\mathrm{V} 600 \mathrm{E}}$ inhibitor Dabrafenib in now mainly used for the treatment of patients with unresectable or metastatic melanoma in combination with Trametinib (a MEK ATP-noncompetitive modulator). ${ }^{72,73}$ Similarly, Encorafenib (a B-Raf ${ }^{\mathrm{V} 600 \mathrm{E}}$ inhibitor) is used in combination with Binimetinib for the treatment of the same diseases, since their approval in 2018. ${ }^{72}$ The importance of B-Raf as a therapeutic relevant target in polytherapies is also testified by the number of combinations including Vemurafenib, Dabrafenib and Encorafenib, with the MEK inhibitors Trametenib and Binimetinib, and Cetuximab that are currently under clinical evaluation, for example, against colorectal cancer (e.g., ClinicalTrials.gov identifiers: NCT03727763, NCT03693170 and NCT04673955). Besides, several clinical studies have also been reported on the investigation of mutant selective B-Raf inhibitors, with modulators of non-kinase proteins, one among the most studied being Hsp90 (e.g., ClinicalTrials.gov identifiers: NCT01657591 and NCT02721459). ${ }^{68-70}$ The selection of the most suitable targets for combination therapy approaches is generally driven by their involvement in relevant oncogenic processes. For example, several mechanisms by which tumor cells can exert drug resistance to B-Raf inhibitors derive by deregulation or overexpression of other oncoproteins, ${ }^{18-20,74,75}$ many of them being "clients" of Hsp90. ${ }^{76,77}$ Consequently, the simultaneous targeting of Hsp90 and B-Raf have represented an attractive strategy to overcome drug resistance to B-Raf inhibitors so far. Indeed, several biological studies and clinical evidence demonstrated that the inhibition of Hsp90 helps to overcome resistance to known blockers of B-Raf, and that their combined inhibition provides synergistic effects in different cancer-related contexts. ${ }^{78-80}$ In line with the polypharmacology concept, further advantages can also be envisioned for cancer treatment on the design of ligands endowed with multi-target activity (Figure 1).

In the case of B-Raf, several studies describing the design of multi-target ligands have been reported so far. ${ }^{81-86}$ In particular, Anighoro et al. ${ }^{81}$ reported in 2017 the identification of the first two compounds endowed with activity towards B-Raf and Hsp90, demonstrating that these targets share overlapping chemical spaces. The compounds reported in this study were identified by means of an integrated in silico strategy and represent valuable starting points for the development of innovative B-Raf/Hsp90 dual inhibitors, especially considering that they showed balanced multitarget activity and low molecular weight. Of note, Hsp90 and B-Raf belong to different protein families and present distinct binding site architectures, which makes the design of dual ligands of these proteins a difficult task. The interest around Hsp90 and B-Raf as partners in polypharmacology strategies has also been further explored more recently within an effort to identify ligands endowed with Hsp90/PDHK1/B-Raf multi-target activity. ${ }^{82}$ The identification of compounds with such a tailored polypharmacology profile would enable the modulation of multiple pathways important to survival and proliferation of tumor cells, thus resulting in more effective anticancer therapies. However, the obtainment of Hsp90/ PDHK1/B-Raf multi-target inhibitors is very challenging, as several, often conflicting, structural requirements should be taken into account in the ligand design process.

Besides, B-Raf has also been framed into multi-target ligand design projects including other kinases, such as VEGFR-2, p38 $\alpha$ and EGFR. ${ }^{83-86}$ In particular, several studies reported the identification of dual inhibitors of the B-Raf and VEGFR-2 kinases. ${ }^{85,87,88}$ The rationale behind the selection of B-Raf and VEGFR-2 for the development of multi-target inhibitors stands on the fact that these proteins fulfill complementary leading roles on processes related to cancer development and progression. ${ }^{89,90}$ For similar reasons, research efforts have also been performed for the design of B-Raf/ p38 $\alpha$ dual inhibitors. ${ }^{86,91}$ Of note, continuous research has also been done for the targeting B-Raf and EGFR, either via combination of selective kinase inhibitors, or with polypharmacology ligands. For example, the inhibition of these targets has already been explored on colorectal cancer by means of combination of drugs, as drug resistance that derives by overexpression and activation of EGFR could be overcome through the blockage of B-Raf, according to recent studies. $^{20,92}$ The design of B-Raf/EGFR dual inhibitors has also been probed as a strategy to overcome drug resistance observed on melanoma and colorectal cancers to approved B-Raf ${ }^{\mathrm{V} 600 \mathrm{E}}$ drugs, providing promising results. Whereas reservations have been very recently raised on the dual inhibition of these targets as a therapeutic opportunity for NSCLC patients. ${ }^{93}$ Although particularly challenging, possibilities on the identification of innovative B-Raf/EGFR dual inhibitors could also be envisioned on type III allosteric contexts. Indeed, B-Raf and EGFR present structurally similar type III allosteric pockets, ${ }^{55}$ which make them ideal candidates for the design of multi-target ligands, for example, by means of computational structure-based approaches as docking. ${ }^{94,95}$ 
In recent years, increased research interests have also arisen around PROTACs (i.e., proteolysis targeting chimeras) for targeting several therapeutic targets (Figure 1). ${ }^{14,96,97}$ Such an approach generally employs bidentate molecules bearing to two covalently bounded chemical moieties, one with high affinity towards the target of interest and the other recruiting specific components of the proteasomal degradation system, to promote selective intracellular proteolysis (e.g., an E3 ligase as VHL). ${ }^{98,99}$ At present, PROTACs with high substrate specificity have been reported for targeting different protein kinases, ${ }^{14}$ including also mutant B-Raf. ${ }^{14,100,101}$ One example of such B-Raf mutant-selective PROTACs comes from a recent study by Alabi et al., ${ }^{102}$ in which the authors designed a compound (e.g., SJF-0628) showing high selectivity towards degradation of $\mathrm{B}-\mathrm{Raf}^{\mathrm{V} 600 \mathrm{E}}$. Although being still at their infancy, approaches based on the targeting of B-Raf with PROTACs technology are expected to provided novel valuable opportunities for cancer treatment. Indeed, such approaches allow to also promote complete removal of the protein scaffold other than blocking its catalytic functions, which might represent a valuable advantage over already reported ATP-competitive inhibitors.

Targeting protein kinases, such as B-Raf, has provided several therapeutic advantages in cancer treatment so far, as also testified by the number of approved drugs and clinical candidates modulating the activity of these proteins that are currently under investigation. ${ }^{14}$ B-Raf has acted as a major player in this context, with some of its ATP-competitive inhibitors (e.g., Sorafenib, Vemurafenib, Dabrafenib and Encorafenib) being approved for the treatment of patients with unresectable or metastatic melanoma in the last two decades. ${ }^{14}$ Although B-Raf ${ }^{\mathrm{V} 600 \mathrm{E}}$ inhibitors provided remarkable advantages in anticancer therapeutic regimens, several limitations could still be envisioned for these compounds, the most relevant being the establishment of drug resistance, paradoxical activation mediated by Raf dimerization and transactivation, and low efficacy towards Ras mutated cancers. ${ }^{38}$ Different strategies based on classic ATP-competitive singletargeting approaches are still being under study to overcome such limitations, some of them showing good premises. ${ }^{13}$ However, novel, and perhaps more valuable, opportunities can be envisioned on approaches targeting the allosteric sites of B-Raf proteins. Indeed, such approaches have already demonstrated to provide remarkable opportunities on other therapeutic-relevant kinases exhibiting high structural similarity with B-Raf. ${ }^{52}$ Moreover, the activity of allosteric kinase inhibitors is less prone to be affected by insurgence of drug resistance deriving by site point mutations with respect to ATP-competitive binders, ${ }^{41}$ this being a significant advantage in anticancer therapy. Importantly, the modulation of B-Raf by means of allosteric ligands would open to complementary approaches including also already reported ATPcompetitive inhibitors to promote more efficient arrest the kinase activity, which is expected to result in improved therapeutic outcomes. ${ }^{43,44}$ In the near future, increasing research efforts will also be addressed towards the identification of multi-target inhibitors modulating B-Raf activity. Indeed, the importance of polypharmacology approaches for kinase targeting is well established, ${ }^{103}$ as also testified by the increasing number of dual inhibitors targeting B-Raf reported in the literature over the last years. ${ }^{81-86}$ The selection of suitable combinations of targets for the rational design of B-Raf polypharmacology ligands is of primary importance in this context, the identification of those providing the highest therapeutic effectiveness being very often difficult. However, recent innovations on computational approaches are expected to aid on their identification. ${ }^{104}$ Similar considerations can also be drawn for the identification of inhibitors targeting B-Raf through innovative mechanisms among already approved drugs, as recently observed for Ponatinib. ${ }^{56}$ Moreover, approaches based on PROTACs technology are also expected to bring significant chemical novelty on future B-Raf inhibitors design, as such compounds exert their activity through molecular mechanisms that are completely different with respect to those of approved drugs and compounds under investigation. The design of either allosteric, polypharmacology or PROTAC ligands targeting B-Raf proteins is challenging, especially with respect of classic kinase APT-competitive binders. However, the recent advancements on understanding cancer cells biology and the improvements on experimental techniques and in silico approaches available for the analysis of information reported in public databases, will certainly facilitate the identification of novel B-Raf inhibitors acting through such innovative mechanisms.

\section{Data availability}

No data are associated with this article.

\section{Author contributions}

L.P.: Conceptualization, Writing - Original Draft Preparation, Writing - Review \& Editing.

\section{Acknowledgments}

The author is pleased to acknowledge Professor Giulio Rastelli (University of Modena and Reggio Emilia) for the helpful advices and fruitful discussion. 
1. Dienstmann $R$, Tabernero J: BRAF as a Target for Cancer Therapy. Anti Cancer Agents Med. Chem. 2011; 11(3): 285-295. Publisher Full Text

2. Karasarides $\mathrm{M}$, Chiloeches $\mathrm{A}$, Hayward R, et al.: B-RAF is a therapeutic target in melanoma. Oncogene 2004; 23(37): 6292-6298.

Publisher Full Text

3. Wellbrock C, Karasarides M, Marais R: The RAF proteins take centre stage. Nat. Rev. Mol. Cell Biol. 2004; 5(11): 875-885. PubMed Abstract | Publisher Full Text

4. Steelman LS, Pohnert SC, Shelton JG, et al.:JAK/STAT, Raf/MEK/ERK, PISK/Akt and BCR-ABL in cell cycle progression and leukemogenesis. Leukemia 2004; 18(2): 189-218. PubMed Abstract | Publisher Full Text

5. Hilger RA, Scheulen ME, Strumberg D: The Ras-Raf-MEK-ERK Pathway in the Treatment of Cancer. Oncol. Res. Treat. 2002; 25(6): 511-518.

Publisher Full Text

6. Garnett MJ, Marais R: Guilty as charged: B-RAF is a human oncogene. Cancer Cell 2004; 6(4): 313-319. Publisher Full Text

7. Zhang W, Liu HT: MAPK signal pathways in the regulation of cell proliferation in mammalian cells. Cell Res. 2002; 12(1): 9-18. Publisher Full Text

8. Avruch J, Khokhlatchev A, Kyriakis JM, et al.: Ras activation of the Raf kinase: tyrosine kinase recruitment of the MAP kinase cascade. Recent Prog. Horm. Res. 2001; 56: 127-156. PubMed Abstract | Publisher Full Text

9. Alqathama A: BRAF in malignant melanoma progression and metastasis: potentials and challenges. Am. J. Cancer Res. 2020; 10 (4): 1103-1114.

10. Wan PTC, Garnett MJ, Roe SM, et al.: Mechanism of Activation of the RAF-ERK Signaling Pathway by Oncogenic Mutations of B-RAF. Cell 2004; 116(6): 855-867. PubMed Abstract | Publisher Full Text

11. McCubrey JA, Steelman LS, Chappell WH, et al.: Roles of the Raf/MEK/ERK pathway in cell growth, malignant transformation and drug resistance. Biochim. Biophys. Acta 2007; 1773(8): 1263-1284.

PubMed Abstract | Publisher Full Text

12. Zaman A, Wu W, Bivona TG: Targeting Oncogenic BRAF: Past, Present, and Future. Cancers. 2019; 11(8): 1197. PubMed Abstract | Publisher Full Text

13. Karoulia Z, Gavathiotis E, Poulikakos PI: New perspectives for targeting RAF kinase in human cancer. Nat. Rev. Cancer 2017; 17 (11): 676-691.

PubMed Abstract | Publisher Full Text

14. Attwood MM, Fabbro D, Sokolov AV, et al.: Trends in kinase drug discovery: targets, indications and inhibitor design. Nat. Rev. Drug Discov. 2021; 20(11): 839-861.

15. Grassi E, Corbelli J, Papiani G, et al.: Current Therapeutic Strategies in BRAF-Mutant Metastatic Colorectal Cancer. Front. Oncol. 2021; 11: 601722 .

PubMed Abstract | Publisher Full Text

16. Chapman PB, Hauschild A, Robert C, et al.: Improved survival with vemurafenib in melanoma with BRAF V600E mutation. $N$. Engl. J. Med. 2011; 364(26): 2507-2516.

17. Villanueva J, Vultur A, Herlyn M: Resistance to BRAF Inhibitors: Unraveling Mechanisms and Future Treatment Options. Cancer Res. 2011; 71(23): 7137-7140.

PubMed Abstract | Publisher Full Text

18. Shtivelman E, Davies MQA, Hwu P, et al.: Pathways and therapeutic targets in melanoma. Oncotarget 2014; 5(7): 1701-1752.

19. Manzano JL, Layos L, Bugés C, et al.: Resistant mechanisms to BRAF inhibitors in melanoma. Ann. Transl. Med. 2016; 4(12): 237. PubMed Abstract | Publisher Full Text

20. Yaeger R, Yao Z, Hyman DM, et al.: Mechanisms of Acquired Resistance to BRAF V600E Inhibition in Colon Cancers Converge on RAF Dimerization and Are Sensitive to Its Inhibition. Cancer Res. 2017; 77(23): 6513-6523. PubMed Abstract | Publisher Full Text

21. Poulikakos PI, Zhang C, Bollag G, et al.: RAF inhibitors transactivate RAF dimers and ERK signalling in cells with wildtype BRAF. Nature 2010; 464(7287): 427-430. PubMed Abstract | Publisher Full Text

22. Hatzivassiliou G, Song K, Yen I, et al.: RAF inhibitors prime wildtype RAF to activate the MAPK pathway and enhance growth.
Nature 2010; 464(7287): 431-435.

PubMed Abstract | Publisher Full Text

23. Anforth RM, Blumetti TCMP, Kefford RF, et al.: Cutaneous manifestations of dabrafenib (GSK2118436): a selective inhibitor of mutant BRAF in patients with metastatic melanoma. Br. J. Dermatol. 2012; 167(5): 1153-1160. PubMed Abstract | Publisher Full Text

24. Lavoie H, Thevakumaran N, Gavory G, et al.: Inhibitors that stabilize a closed RAF kinase domain conformation induce dimerization. Nat. Chem. Biol. 2013; 9(7): 428-436. PubMed Abstract | Publisher Full Text

25. Anforth R, Fernandez-Peñas $P$, Long GV: Cutaneous toxicities of RAF inhibitors. Lancet Oncol. 2013; 14(1): e11-e18. Publisher Full Text

26. Lacouture ME, Duvic M, Hauschild A, et al.: Analysis of dermatologic events in Vemurafenib-treated patients with melanoma. Oncologist 2013; 18(3): 314-322.

PubMed Abstract | Publisher Full Text

27. Cichowski K, Jänne PA: Inhibitors that activate. Nature 2010; 464(7287): 358-359. Publisher Full Tex

28. Agianian B, Gavathiotis E: Current insights of BRAF inhibitors in cancer. J. Med. Chem. 2018; 61(14): 5775-5793.

29. Jin T, Lavoie $H$, Sahmi M, et al.: RAF inhibitors promote RAS-RAF interaction by allosterically disrupting RAF autoinhibition. Nat. Commun. 2017; 8(1): 1211. PubMed Abstract | Publisher Full Text

30. Yao Z, Torres NM, Tao A, et al.: BRAF Mutants Evade ERKDependent Feedback by Different Mechanisms that Determine Their Sensitivity to Pharmacologic Inhibition. Cancer Cell 2015; 28(3): 370-383.

31. Karoulia Z, Wu Y, Ahmed TA, et al: : An Integrated Model of RAF Inhibitor Action Predicts Inhibitor Activity against Oncogenic BRAF Signaling. Cancer Cell 2016; 30(3): 485-498. PubMed Abstract | Publisher Full Text

32. Okaniwa $M$, Hirose $M$, Arita $T$, et al.: Discovery of a Selective Kinase Inhibitor (TAK-632) Targeting Pan-RAF Inhibition: Design, Synthesis, and Biological Evaluation of C-7-Substituted 1,3Benzothiazole Derivatives. J. Med. Chem. 2013; 56(16): 6478-6494.

33. Henry JR, Kaufman MD, Peng S-B, et al.: Discovery of 1-(3,3Dimethylbutyl)-3

(2-fluoro-4-methyl-5-(7-methyl-2-(methylamino)pyrido[2,3-d] pyrimidin-6-yl)phenyl) urea (LY3009120) as a Pan-RAF Inhibitor with Minimal Paradoxical Activation and Activity against BRAF or RAS Mutant Tumor Cells. J. Med. Chem. 2015; 58(10): 4165-4179. PubMed Abstract | Publisher Full Text

34. Girotti MR, Lopes F, Preece N, et al.: Paradox-Breaking RAF Inhibitors that Also Target SRC Are Effective in Drug-Resistant BRAF Mutant Melanoma. Cancer Cell 2015; 27(1): 85-96. PubMed Abstract | Publisher Full Text

35. Koelblinger $P$, Thuerigen O, Dummer R: Development of encorafenib for BRAF-mutated advanced melanoma. Curr. Opin. Oncol. 2018; 30(2): 125-133.

36. Zhang C, Spevak W, Zhang Y, et al.: RAF inhibitors that evade paradoxical MAPK pathway activation. Nature 2015; 526(7574): 583-586. PubMed Abstract | Publisher Full Text

37. Wichmann J, Rynn C, Friess T, et al.: Preclinical Characterization of a Next-Generation Brain Permeable, Paradox Breaker BRAF Inhibitor. Clin. Cancer Res. 2021. PubMed Abstract | Publisher Full Text

38. Cook FA, Cook SJ: Inhibition of RAF dimers: it takes two to tango. Biochem. Soc. Trans. 2020; 49(1): 237-251.

39. Gagic Z, Ruzic D, Djokovic N, et al.: In silico methods for design of kinase inhibitors as anticancer drugs. Front. Chem. 2019; 7: 873.

40. Bhullar KS, Lagarón NO, McGowan EM, et al.: Kinase-targeted cancer therapies: progress, challenges and future directions. Mol. Cancer 2018: 17(1): 48 . PubMed Abstract | Publisher Full Text

41. Lu X, Smaill JB, Ding K: New Promise and Opportunities for Allosteric Kinase Inhibitors. Angew. Chem. Int. Ed. Engl. 2020; 59 (33): 13764-13776. PubMed Abstract | Publisher Full Text

42. Wu P, Clausen MH, Nielsen TE: Allosteric small-molecule kinase inhibitors. Pharmacol. Ther. 2015; 156: 59-68. Publisher Full Text

43. Beneker CM, Rovoli M, Kontopidis G, et al.: Design and Synthesis of Type-IV Inhibitors of BRAF Kinase That Block Dimerization and Overcome Paradoxical MEK/ERK Activation. J. Med. Chem. 2019; 
62(8): 3886-3897.

PubMed Abstract | Publisher Full Text

44. Gunderwala AY, Nimbvikar AA, Cope NJ, et al.: Development of Allosteric BRAF Peptide Inhibitors Targeting the Dimer Interface of BRAF. ACS Chem. Biol. 2019; 14(7): 1471-1480. PubMed Abstract | Publisher Full Text

45. Maity S, Pai KSR, Nayak Y: Advances in targeting EGFR allosteric site as anti-NSCLC therapy to overcome the drug resistance. Pharmacol. Rep. 2020; 72(4): 799-813.

46. Carlino L, Christodoulou MS, Restelli V, et al.: Structure-Activity Relationships of Hexahydrocyclopenta [c] quinoline Derivatives as Allosteric Inhibitors of CDK2 and EGFR. ChemMedChem 2018; 13 (24): 2627-2634

PubMed Abstract | Publisher Full Text

47. Caporuscio F, Tinivella A, Restelli V, et al.: Identification of smallmolecule EGFR allosteric inhibitors by high-throughput docking. Fut. Med. Chem. 2018; 10(13): 1545-1553. PubMed Abstract | Publisher Full Text

48. Hindie $V$, Stroba A, Zhang $H$, et al.: Structure and allosteric effects of low-molecular-weight activators on the protein kinase PDK1. Nat. Chem. Biol. 2009; 5(10): 758-764.

PubMed Abstract | Publisher Full Text

49. Rice KD, Aay N, Anand NK, et al.: Novel Carboxamide-Based Allosteric MEK Inhibitors: Discovery and Optimization Efforts toward XL518 (GDC-0973). ACS Med. Chem. Lett. 2012; 3(5): 416-421. PubMed Abstract | Publisher Full Text

50. Hatzivassiliou G, Haling JR, Chen $\mathrm{H}$, et al.: Mechanism of MEK inhibition determines efficacy in mutant KRAS- versus BRAFdriven cancers. Nature 2013; 501(7466): 232-236. PubMed Abstract | Publisher Full Text

51. Jia $Y$, Yun C-H, Park E, et al.: Overcoming EGFR(T790M) and EGFR(C797S) resistance with mutant-selective allosteric inhibitors. Nature 2016; 534(7605): 129-132. PubMed Abstract | Publisher Full Text

52. To C, Jang J, Chen T, et al.: Single and dual targeting of mutant EGFR with an allosteric inhibitor. Cancer Discov. 2019; 9(7): 926-943.

PubMed Abstract | Publisher Full Text

53. Khan ZM, Real AM, Marsiglia WM, et al.: Structural basis for the action of the drug trametinib at KSR-bound MEK. Nature 2020; 588(7838): 509-514.

PubMed Abstract | Publisher Full Text

54. Rastelli G, Anighoro A, Chripkova M, et al.: Structure-based discovery of the first allosteric inhibitors of cyclin-dependent kinase 2. Cell Cycle 2014; 13(14): 2296-2305. PubMed Abstract | Publisher Full Text

55. Sturm N, Tinivella A, Rastelli G: Exploration and comparison of the geometrical and physicochemical properties of an ac allosteric pocket in the structural kinome. J. Chem. Inf. Model. 2018; 58(5): 1094-1103.

PubMed Abstract | Publisher Full Text

56. Cotto-Rios XM, Agianian B, Gitego N, et al.: Inhibitors of BRAF dimers using an allosteric site. Nat. Commun. 2020; 11(1): 4370. PubMed Abstract | Publisher Full Text

57. Li Y, Guo B, Xu Z, et al.: Repositioning organohalogen drugs: a case study for identification of potent B-Raf V600E inhibitors via docking and bioassay. Sci. Rep. 2016; 6(1): 31074 PubMed Abstract | Publisher Full Text

58. Pushpakom S, Iorio F, Eyers PA, et al.: Drug repurposing: progress, challenges and recommendations. Nat. Rev. Drug Discov. 2019; 18(1): 41-58.

PubMed Abstract | Publisher Full Text

59. Rastelli G, Pellati F, Pinzi L, et al.: Repositioning Natural Products in Drug Discovery. Molecules 2020; 25(5): 1154

PubMed Abstract | Publisher Full Text

60. Sleire $\mathrm{L}$, Førde $\mathrm{HE}$, Netland IA, et al.: Drug repurposing in cancer. Pharmacol. Res. 2017; 124: 74-91.

Publisher Full Text

61. Farha MA, Brown ED: Drug repurposing for antimicrobial discovery. Nat. Microbiol. 2019; 4(4): 565-577. Publisher Full Text

62. Pinzi $L$, Lherbet $C$, Baltas $M$, et al.: In silico repositioning of Cannabigerol as a novel inhibitor of the Enoyl Acyl Carrie Protein (ACP) Reductase (InhA). Molecules 2019; 24(14): 2567. PubMed Abstract | Publisher Full Text

63. Brighenti $\mathrm{V}$, Iseppi R, Pinzi L, et al.: Antifungal Activity and DNA Topoisomerase Inhibition of Hydrolysable Tannins from Punica granatum L. Int. J. Mol. Sci. 2021; 22(8): 4175 Publisher Full Text

64. Pinzi L, Tinivella A, Caporuscio F, et al.: Drug repurposing and polypharmacology to fight SARS-CoV-2 through inhibition of the
Main Protease. Front. Pharmacol. 2021; 12: 636989.

PubMed Abstract | Publisher Full Text

65. Freeman AK, Ritt DA, Morrison DK: Effects of Raf dimerization and its inhibition on normal and disease-associated Raf signaling. Mol. Cell 2013; 49(4): 751-758.

66. Cope NJ, Novak B, Liu Z, et al.: Analyses of the oncogenic BRAFD594G variant reveal a kinase-independent function of BRAF in activating MAPK signaling. J. Biol. Chem. 2020; 295(8): 2407-2420.

PubMed Abstract | Publisher Full Text

67. Martinez R, Defnet A, Shapiro P: Avoiding or Co-Opting ATP Inhibition: overview of type III, IV, V, and VI Kinase Inhibitors Shapiro P, editor. Next Generation Kinase Inhibitors: Moving Beyond the ATP Binding/Catalytic Sites Cham: Springer International Publishing; 2020; pp. 29-59.

68. Anighoro A, Bajorath J, Rastelli G: Polypharmacology: Challenges and Opportunities in Drug Discovery. J. Med. Chem. 2014; 57(19): 7874-7887.

PubMed Abstract | Publisher Full Text

69. Rastelli G, Pinzi L: Computational polypharmacology comes of age. Front. Pharmacol. 2015; 6: 157.

70. Reddy AS, Zhang S: Polypharmacology: drug discovery for the future. Expert. Rev. Clin. Pharmacol. 2013; 6(1): 41-47. PubMed Abstract | Publisher Full Text

71. Bayat Mokhtari R, Homayouni TS, Baluch N, et al.: Combination therapy in combating cancer. Oncotarget 2017; 8(23): 38022-38043.

PubMed Abstract | Publisher Full Text

72. Proietti I, Skroza N, Michelini S, et al.: BRAF inhibitors: molecular targeting and immunomodulatory actions. Cancers. 2020; 12(7): 1823.

PubMed Abstract | Publisher Full Text

73. Robert C, Karaszewska B, Schachter J, et al.: Improved Overall Survival in Melanoma with Combined Dabrafenib and Trametinib. N. Engl. J. Med. 2015; 372(1): 30-39.

74. Shi $\mathrm{H}$, Hugo $\mathrm{W}$, Kong $\mathrm{X}$, et al.: Acquired resistance and clonal evolution in melanoma during BRAF inhibitor therapy. Cancer Discov. 2014; 4(1): 80-93.

PubMed Abstract | Publisher Full Text

75. Rizos H, Menzies AM, Pupo GM, et al.: BRAF inhibitor resistance mechanisms in metastatic Melanoma: spectrum and clinical impact. Clin. Cancer Res. 2014; 20(7): 1965-1977. PubMed Abstract | Publisher Full Text

76. Trepel J, Mollapour M, Giaccone G, et al.: Targeting the dynamic HSP90 complex in cancer. Nat. Rev. Cancer 2010; 10(8): 537-549. PubMed Abstract | Publisher Full Text

77. da Rocha DS, Friedlos F, Light Y, et al.: Activated B-RAF is an Hsp90 client protein that is targeted by the anticancer drug 17-Allylamino-17-Demethoxygeldanamycin. Cancer Res. 2005 65(23): 10686-10691. Publisher Full Text

78. Paraiso KHT, Haarberg HE, Wood E, et al.: The HSP90 inhibitor XL888 overcomes BRAF inhibitor resistance mediated through diverse mechanisms. Clin. Cancer Res. 2012; 18(9): 2502-2514.

79. Smyth T, Paraiso KHT, Hearn K, et al.: Inhibition of HSP90 by AT13387 delays the emergence of resistance to BRAF inhibitors and overcomes resistance to dual BRAF and MEK inhibition in Melanoma models. Mol. Cancer Ther. 2014; 13(12): 2793-2804.

80. Smith DL, Acquaviva J, Sequeira M, et al.: The HSP90 inhibitor Ganetespib potentiates the antitumor activity of EGFR tyrosine kinase inhibition in mutant and wild-type non-small cell lung cancer. Target. Oncol. 2015; 10(2): 235-245. PubMed Abstract | Publisher Full Text

81. Anighoro A, Pinzi L, Marverti G, et al.: Heat Shock Protein 90 and Serine/Threonine kinase B-Raf inhibitors have overlapping chemical space. RSC Adv. 2017; 7(49): 31069-31074. Publisher Full Text

82. Pinzi L, Foschi F, Christodoulou MS, et al.: Design and Synthesis of Hsp90 Inhibitors with B-Raf and PDHK1 Multi-Target Activity. ChemistryOpen. 2021; 10(12): 1177-1185. PubMed Abstract | Publisher Full Text

83. Cheng $\mathrm{H}$, Chang $\mathrm{Y}$, Zhang $\mathrm{L}$, et al.: Identification and optimization of new dual inhibitors of B-Raf and Epidermal Growth Factor Receptor kinases for overcoming resistance against Vemurafenib. J. Med. Chem. 2014; 57(6): 2692-2703. PubMed Abstract | Publisher Full Text

84. Al-Wahaibi LH, Gouda AM, Abou-Ghadir OF, et al.: Design and synthesis of novel 2,3-dihydropyrazino[1,2-a]indole-1,4-dione derivatives as antiproliferative EGFR and BRAFV600E dual inhibitors. Bioorg. Chem. 2020; 104: 104260. PubMed Abstract | Publisher Full Text 
85. Abdel-Mohsen HT, Omar MA, El Kerdawy AM, et al.: Novel potent substituted 4-amino-2-thiopyrimidines as dual VEGFR-2 and BRAF kinase inhibitors. Eur. J. Med. Chem. 2019; 179: 707-722.

PubMed Abstract | Publisher Full Text

86. Ali EMH, El-Telbany RFA, Abdel-Maksoud MS, et al.: Design, synthesis, biological evaluation, and docking studies of novel (imidazol-5-yl)pyrimidine-based derivatives as dual BRAFV600E/ p38a inhibitors. Eur. J. Med. Chem. 2021; 215: 113277. PubMed Abstract | Publisher Full Text

87. Wang $Y$, Wan $S$, Li Z, et al.: Design, synthesis, biological evaluation and molecular modeling of novel $1 \mathrm{H}$-pyrazolo[3,4-d] pyrimidine derivatives as BRAFV600E and VEGFR-2 dual inhibitors. Eur. J. Med. Chem. 2018; 155: 210-228. PubMed Abstract | Publisher Full Text

88. Okaniwa M, Hirose M, Imada T, et al.: Design and synthesis of novel DFG-Out RAF/Vascular Endothelial Growth Factor Receptor 2 (VEGFR2) inhibitors. 1. Exploration of $[5,6]$-fused bicyclic scaffolds. J. Med. Chem. 2012; 55(7): 3452-3478. PubMed Abstract | Publisher Full Text

89. Alavi A, Hood JD, Frausto R, et al.: Role of Raf in vascular protection from distinct apoptotic stimuli. Science 2003; 301(5629): 94-96. PubMed Abstract | Publisher Full Text

90. Hood JD, Bednarski M, Frausto R, et al.: Tumor regression by targeted gene delivery to the neovasculature. Science 2002; 296(5577): 2404-2407.

PubMed Abstract | Publisher Full Text

91. Youssif BGM, Gouda AM, Moustafa AH, et al:: Design and synthesis of new triarylimidazole derivatives as dual inhibitors of BRAFV600E/p38 $\alpha$ with potential antiproliferative activity. J. Mol. Struct. 2022; 1253: 132218. Publisher Full Text

92. Yao YM, Donoho GP, Iversen PW, et al.: Mouse PDX trial suggests synergy of concurrent inhibition of RAF and EGFR in colorecta cancer with BRAF or KRAS mutations. Clin. Cancer Res. 2017; 23(18): 5547-5560.

PubMed Abstract | Publisher Full Text

93. Oh S, Lim JH, Park N, et al.: Dual inhibition of EGFR and BRAF can be harmful in patients harboring an EGFR-activating mutation. J. Thorac. Oncol. 2020; 15(3): e32-e34. PubMed Abstract | Publisher Full Text
94. Pinzi L, Caporuscio F, Rastelli G: Selection of protein conformations for structure-based polypharmacology studies. Drug Discov. Today 2018; 23(11): 1889-1896. PubMed Abstract | Publisher Full Text

95. Pinzi L, Rastelli G: Molecular docking: shifting paradigms in drug discovery. Int. J. Mol. Sci. 2019; 20(18): 4331. PubMed Abstract | Publisher Full Text

96. Lai AC, Crews CM: Induced protein degradation: an emerging drug discovery paradigm. Nat. Rev. Drug Discov. 2017; 16(2): 101-114. PubMed Abstract | Publisher Full Text

97. Burslem GM, Crews CM: Proteolysis-targeting chimeras as therapeutics and tools for biological discovery. Cell 2020; 181(1): 102-114.

PubMed Abstract | Publisher Full Text

98. Sakamoto KM, Kim KB, Kumagai A, et al.: Protacs: chimeric molecules that target proteins to the Skp1-Cullin-F box complex for ubiquitination and degradation. Proc. Natl. Acad. Sci. U. S. A. 2001; 98(15): 8554-8559. PubMed Abstract | Publisher Full Text

99. Salami J, Crews CM: Waste disposal-An attractive strategy for cancer therapy. Science 2017; 355(6330): 1163-1167. Publisher Full Text

100. Posternak G, Tang $X$, Maisonneuve $P$, et al.: Functional characterization of a PROTAC directed against BRAF mutant V600E. Nat. Chem. Biol. 2020; 16(11): 1170-1178. PubMed Abstract | Publisher Full Text

101. Han $X-R$, Chen $L$, Wei $Y$, et al.: Discovery of selective small molecule degraders of BRAF-V600E. J. Med. Chem. 2020; 63(8): 4069-4080. PubMed Abstract | Publisher Full Text

102. Alabi $S$, Jaime-Figueroa $S$, Yao Z, et al.: Mutant-selective degradation by BRAF-targeting PROTACs. Nat. Commun. 2021; 12(1): 920

PubMed Abstract | Publisher Full Text

103. Garuti L, Roberti M, Bottegoni G: Multi-kinase inhibitors. Curr Med. Chem. 2015; 22(6): 695-712. Publisher Full Text

104. Proschak E, Stark H, Merk D: Polypharmacology by design: a medicinal chemist's perspective on multitargeting compounds. J. Med. Chem. 2019; 62(2): 420-444. PubMed Abstract | Publisher Full Text 


\section{Open Peer Review}

\section{Current Peer Review Status:}

\section{Version 1}

Reviewer Report 15 March 2022

https://doi.org/10.5256/f1000research.120182.r125513

(C) 2022 Anighoro A. This is an open access peer review report distributed under the terms of the Creative Commons Attribution License, which permits unrestricted use, distribution, and reproduction in any medium, provided the original work is properly cited.

\section{Andrew Anighoro \\ Relation Therapeutics LTD, London, UK}

The author gives an overview of B-Raf as a known target for cancer related diseases. Then, provides an account of design strategies that may overcome some limitations of typical ATP competitive drugs.

- The author mostly refers to B-Raf as a target validated by "recent" evidence/studies, while it has been described in the literature as an oncogene at least from the 90 s and Vemurafenib began clinical testing in 2008 to be approved in 2011 by FDA followed shortly by other drugs. I don't think this makes the article less interesting, but I feel that B-Raf should be referred sometimes in the text with adjectives such as "well established" rather than "recent".

Would it be possible to give the reader an idea of how the aC-helix is structurally related to the ATP binding site? Maybe through a sentence in the text and/or marking it in Figure 1?

When writing "activation loop", "activation segment" and "aC-helix" are italics and quotes necessary? aC-helix has already been used several times in the text up until then without quotes or italics.

I think that the sentence "recent advancements in crystallographic and in silico techniques will certainly help to overcome several of the issues currently encountered in kinase allosteric ligand design" should be followed by at least mentioning some examples of techniques that the author is certain are going to help.

Can it be explained more explicitly why Ponatinib/PHI1 do not qualify as allosteric inhibitors?

Would it be possible to include a comment on the challenge of rationally designing kinase multitarget inhibitors given the selectivity issues mentioned by the author?

The first time that the term PROTAC is mentioned, it should be by the full name followed by 
the abbreviation, proteolysis targeting chimera (PROTAC).

"(e.g., an E3 ligase as VHL)" Probably, CRBN should be mentioned as well. Both should be mentioned by their full name first.

Probably, "e.g." in Figure 1 when addressing E3 ligases can be removed as it makes it look like E3 ligases can be replaced by something else in the context of PROTACs. I am not aware if that's actually possible, but if that's the case, it should be mentioned in the text.

In the abstract and in the main text the word premises is used a few times instead of promise, I believe.

Is the topic of the opinion article discussed accurately in the context of the current literature?

Yes

Are all factual statements correct and adequately supported by citations?

Yes

Are arguments sufficiently supported by evidence from the published literature? Yes

Are the conclusions drawn balanced and justified on the basis of the presented arguments? Partly

Competing Interests: No competing interests were disclosed.

Reviewer Expertise: Drug discovery, computational chemistry.

I confirm that I have read this submission and believe that I have an appropriate level of expertise to confirm that it is of an acceptable scientific standard, however I have significant reservations, as outlined above.

Author Response 16 Apr 2022

Luca Pinzi

I would like to thank the Reviewer for the comments and the precious suggestions. The manuscript was revised to better contextualize the development of innovative B-Raf targeting approaches, with respect to established efforts (e.g., ATP-competitive inhibitors development). Accordingly, the descriptions referring to literature data were also revised under a more contemporary perspective.

A brief description of the main elements characterizing the ATP-binding site of the kinases was reported in the revised version of the manuscript. This helped to delineate how the regulatory aC-helix is related to the other structural regions in the kinases ATP binding site. Besides, Figure 1 was also revised to better highlight the position of the aC-helix, with 
respect to the hinge region in the B-Raf active site to which ATP-competitive inhibitors bind to, and to improve the image contents.

The text was also revised to provide further insights on some of the experimental techniques and in silico approaches that are (and are also expected to be even more in the future) of help for kinase allosteric drug design efforts. Moreover, additional references to relevant literature data were included in the revised version of the manuscript to better contextualize the application of some of these techniques, on both B-Raf related research and a more general perspective.

An explanation of how Ponatinib and PHI1 can be classified according to their experimentally derived binding mode is now provided in the text, as suggested by the Reviewer. As revised, the text is expected to help better contextualize the example reported on Ponatinib/PHI1, with respect to the type III B-Raf allosteric pocket mentioned within this article.

The main challenges that might be faced when rationally designing multi-kinase inhibitors are now discussed in the text. Moreover, the main E3 ligases that have been exploited so far for the design of PROTACs are now reported within the text.

The manuscript was carefully revised, to remove typos and to make it clearer to readers. Moreover, the full names of the reported abbreviations were added within the text where needed.

Competing Interests: No competing interests were disclosed.

Reviewer Report 04 March 2022

https://doi.org/10.5256/f1000research.120182.r125510

(C) 2022 Falchi F. This is an open access peer review report distributed under the terms of the Creative Commons Attribution License, which permits unrestricted use, distribution, and reproduction in any medium, provided the original work is properly cited.

\section{Federico Falchi}

Laboratory of Computational Medicinal Chemistry, Department of Pharmacy and Biotechnology, University of Bologna, Bologna, Italy

In this nice perspective, Pinzi summarizes the current state-of-the-art in the development of B-Raf inhibitors acting through innovative mechanisms. After a brief introduction about the traditional inhibitors (Atp-competitive) with their big limitations, Pinzi describes the most challenging approaches such as the design of allosteric modulators, the polypharmacology, and the PROTACS design with an eye to the computational strategies.

The manuscript is well understandable, offering both a biological and medicinal chemistry point of 
view. The references are adequate.

I do believe that work can be accepted certainly for indexing.

I have only a very few minor remarks:

1. The sentence below is too long:

Besides, other studies have been focused on the development of compounds as PLX7904 and PLX8394, able to escape paradoxical activation of B-Raf (i.e., the so-called "paradox breakers") and to overcome some of known resistance mechanisms associated to previously reported Raf inhibitors,36,37 the latter ligand currently being evaluated in Phase I/IIa clinical trials (ClinicalTrials.gov identifier: NCT02428712).

Please change for example as:

Besides, other studies have been focused on the development of compounds such as PLX7904 and PLX8394, able to escape paradoxical activation of B-Raf (i.e., the so-called "paradox breakers") and to overcome some of the known resistance mechanisms associated with previously reported Raf inhibitors.

PLX8394 is currently being evaluated in Phase I/IIa clinical trials (ClinicalTrials.gov identifier: NCT02428712).

2. The sentence below is too long:

Nevertheless, the results prospected in this study paved the way towards the identification of innovative B-Raf inhibitors among approved drugs (i.e., drug repurposing) (Figure 1), this approach being already navigated also with natural products and clinically safe candidates, on different medicinal chemistry research areas

Please change for example as:

Nevertheless, the results prospected in this study paved the way towards the identification of innovative B-Raf inhibitors among approved drugs (i.e., drug repurposing) (Figure 1). This approach is already been conducted also with natural products and clinically safe candidates in different medicinal chemistry research areas.

3. The abbreviation NSCLC is not straightforward, the first time an abbreviation is used it should be explained.

4. In the image:

- a $B$ in B-RAF is missing

- the bullets points are not all the same

- sometimes a period is used at the end of the sentence, other times not

\section{Is the topic of the opinion article discussed accurately in the context of the current literature?}


Are all factual statements correct and adequately supported by citations? Yes

Are arguments sufficiently supported by evidence from the published literature? Yes

Are the conclusions drawn balanced and justified on the basis of the presented arguments? Yes

Competing Interests: No competing interests were disclosed.

Reviewer Expertise: Drug design and drug development by means of computational techniques.

I confirm that I have read this submission and believe that I have an appropriate level of expertise to confirm that it is of an acceptable scientific standard.

Author Response 16 Apr 2022

Luca Pinzi

I would like to thank the Reviewer for their precious comments. The manuscript was carefully revised, and long sentences split to make the text clearer to readers, in agreement to the Reviewer suggestions. Moreover, the full name of the reported abbreviations was added in the text. Figure 1 was revised to remove typos as suggested and to improve the image contents.

Competing Interests: No competing interests were disclosed.

The benefits of publishing with F1000Research:

- Your article is published within days, with no editorial bias

- You can publish traditional articles, null/negative results, case reports, data notes and more

- The peer review process is transparent and collaborative

- Your article is indexed in PubMed after passing peer review

- Dedicated customer support at every stage

For pre-submission enquiries, contact research@f1000.com 